\title{
Economía feminista: del cuidado a la toma de decisiones
}

\author{
Feminist economy: from care to decision making
}

\author{
María del Carmen Rovira i Zarzoso ${ }^{1}$ \\ Master en Ética y Democracia \\ Universidad de Valencia \\ macrovira@gmail.com \\ Fecha de recepción: 05/08/2019 \\ Fecha de aprobación: 18/10/2019
}

Como citar este artículo: M. ROVIRA i ZARZOSO. "Economía feminista: del cuidado a la toma de decisiones" en Palabra y Razón. Revista de Teología, Filosofía y Ciencias de la Religión No16, Diciembre 2019, pp. $45-67$ https:// doi.org/10.29035/pyr.16.45

Resumen: A nivel mundial, la depreciación que sufren las mujeres en el entorno laboral es multicausal, pero básicamente, el problema radica en el discurso androcentrista que nutre al capitalismo avanzado. El movimiento feminista resurge con fuerza como motor del cambio social, y los gobiernos y las empresas no pueden mantenerse al margen de esta transformación. La economía feminista trata de responder a las nuevas necesidades de esta ciudadanía avanzada, que reivindica la facticidad de derechos sociales y laborales en igualdad: para hombres y mujeres.

Palabras clave: feminismo, ética, economía, empresa, sociedad, política y educación.

\begin{abstract}
The global depreciation suffered by women in their work enviroiment is multicausal. However, the problem basically lies in the androcentric discourse nourishing advanced capitalism. The feminist movement vigorously reappears as a motor of social change and governments, as well as companies, cannot reamin on the sidelines of this transformatios. The feminist economy seeks to respond to the latest needs of this advanced citizenship wich claims the facticity of social and labour rights for men and women on an equal footing.
\end{abstract}

Key words: feminism, ethics, economy, business, society, politics, education.

\footnotetext{
${ }^{1}$ Licenciada en Publicidad y Relaciones Públicas, y Máster en Docencia para Educación Secundaria por la Universitat Jaume I; Máster en Ética y Democracia por la Universidad de Valencia; Posgrado en Literatura y Género por la UNED. Profesora de Lengua y Literatura Castellana del Ministerio de Educación de España. Gracias al profesor CristhianAlmonacid por contar conmigo para este proyecto, y a todos los profesores y compañeros del Máster en Ética y Democracia, por tanto.
} 


\section{Introducción}

Corría el año 1789 cuando las primeras feministas salieron a las calles de París para vindicar su derecho a la ciudadanía. Eran tiempos de revolución. Desde entonces, la lucha por el reconocimiento de la mujer como sujeto activo se ha convertido en uno de los cambios sociales más importantes de la historia de la Humanidad. Si bien es cierto que llegamos al siglo XXI con la teoría bien aprendida: "lo personal es político", en la práctica olvidamos con frecuencia que lo personal también es mercantil.

Sin lugar a dudas, los últimos veinte años han supuesto una mejoría sustancial para las mujeres a nivel social y económico. Esto se debe a que en la mayor parte del mundo se han equiparado las condiciones de participación política entre mujeres y hombres a la hora de determinar sus propias formas de vida. Como consecuencia, el número de mujeres capacitadas que participan hoy en día en el mercado de trabajo no tiene precedentes, y los gobiernos fomentan políticas de igualdad de género con el fin de impulsar el desarrollo económico. A pesar de los avances en materia de igualdad, a nivel global, las mujeres adolecen de capacidades humanas desiguales respecto a los varones ${ }^{2}$. Son estas competencias restringidas las que menguan su potencial en la toma de decisiones políticas y empresariales. Como demuestran los últimos datos ofrecidos por la Organización Mundial del Trabajo (OIT, 2018) ${ }^{3}$, las mujeres no sólo no disponen de las misma posibilidad de participación en el mercado, sino que además tienen más probabilidades de estar desempleadas que ellos.

Estereotipos de género, trabajos sexualizados por sectores, tareas al margen de la seguridad social y de los convenios laborales, empleos no remunerados, son algunas de las desventajas de género a las que se enfrentan las mujeres a diario. A todas estas brechas, habría que sumar también las que derivan de la clase socioeconómica, la edad, el origen étnico y la situación familiar. A pesar todo, no será muy arriesgado afirmar que como consecuencia de todo lo anterior, el movimiento feminista se encuentra en

\footnotetext{
${ }^{2}$ Bajo el título Hacia un futuro mejor para las mujeres en el trabajo: la opinión de las mujeres y de los hombres, el informe Gallup 2018 publica los resultados obtenidos en 142 países y territorios. En su introducción se advierte de que las mujeres, pese a representar la mitad de la población mundial, siguen estando infrarrepresentadas. Además, una brecha de 26 puntos porcentuales separa a las mujeres de los hombres en términos de participación en la fuerza de trabajo, diferencia que aumenta en ciertas regiones del mundo. Del informe se extrae también que las mujeres continúan asumiendo el grueso de las responsabilidades familiares y de asistencia de cuidados. Estas funciones impiden a algunas incorporarse a la fuerza de trabajo, y a otras les dificulta la conciliación laboral y familiar.

${ }^{3}$ La Organización Internacional del Trabajo publicó en marzo de 2018 su informe anual sobre las perspectivas sociales y del empleo en el mundo, OIT. Avance global sobre las tenencias del empleo femenino. Oficina Internacional del Trabajo: Ginebra, 2018, su estudio proporciona una evaluación cuantitativa del alcance y la profundidad de las desventajas a nivel mundial.
} 
un momento álgido en la actualidad ${ }^{4}$. Es en este momento de efervescencia feminista cuando se requiere diálogo entre todos los agentes sociales, políticos y económicos a fin de alcanzar consensos.

El objetivo del presente artículo es demostrar que la depreciación laboral de la mujer no es sino el reflejo de una estructura social excluyente, cuyas prácticas discriminatorias se asientan en políticas flemáticas e inmovilistas. Para ello, analizaremos algunas de las causas de la desigualdad estructural y propondremos algunas soluciones para tratar de erradicarla. Empezaremos buscando el origen en la construcción social; a continuación nos aproximaremos a la relación que mantienen estado y género; y por último hablaremos de la perspectiva de género en la economía y las empresas. Con todo, defenderemos la capacidad y la práctica del diálogo racional como la posibilidad de establecer acuerdos que permitan un discurso favorable hacia la mujer que, en suma, facilite superar la desigualdad de género en el mercado, tanto financiero como laboral.

La tesis que presentamos aquí consiste en rediseñar el lugar de las mujeres en todos los ámbitos, pues la agenda de las mujeres exige un posicionamiento transversal y envolvente. Proponemos avanzar hacia una nueva forma de entender la corresponsabilidad social empresarial en perspectiva de género. A saber, defendemos la práctica del feminismo cooperativo como herramienta actitudinal capaz de aunar sociedad, estado y mercado en el activismo y la toma de decisiones enfocadas hacia la igualdad. Todo para ingeniar un nuevo proyecto social en clave feminista, cimentado en la cooperación entre familia, política y empresa, a fin de lograr el empoderamiento económico de la mujer y la plena igualdad.

\section{Algo está cambiando: diálogo racional para la emergencia feminista}

La cuestión de las mujeres supone el gran desafío para la agenda del siglo XXI. Resolver los problemas derivados de la desigualdad de género es un asunto urgente por dos motivos: porque supone una cuestión de dignidad humana, y porque de su resolución depende el desarrollo económico de las naciones.

Pese a ser la mitad de la población, las mujeres estamos lejos de alcanzar la igualdad real en un mercado pensado y diseñado en masculino. Pero en España, las movilizaciones del pasado ocho de marzo de 2018, Día Internacional de la

\footnotetext{
${ }^{4}$ Tomaremos España como referente para dimensionar el alcance social de esta revolución, puesto que además de ser el contexto desde el que se escribe el presente artículo, España supuso el epicentro europeo de la lucha feminista el pasado 8 de marzo de 2018, en la que vino a llamarse la primera huelga feminista. La elevada participación ciudadana en las movilizaciones realizadas en las principales capitales del país, tuvo una destacada cobertura mediática a nivel internacional. Disponible en: https://politica.elpais.com/politica/2018/03/08/actualidad/1520528768_368042.html
} 
Mujer, demostraron que algo está cambiando. Juicios como el de La Manada (caso emblemático de violencia de género en España $)^{5}$ supusieron un revulsivo social de rechazo y denuncia hacia las prácticas abusivas y de violencia de género, que llevaron a la ciudadanía a tomar las calles en reiteradas ocasiones. Esta cohesión social entorno a la marea morada en España, cobró mayor fuerza gracias a la repercusión mediática de otros movimientos internacionales de denuncia como el \#MeToo, que en España en concreto derivó en el \#Cuéntalo ${ }^{6}$. La visibilidad de todos estos casos no son sino un ejemplo más para llegar a entender el alcance de esta revolución contra la desigualdad de género, que en el caso de España eclosionaron en las concentraciones del que se denominó $8 \mathrm{M}$ de 2018.

Nos encontramos pues ante una nueva ola del feminismo, la Tercera o la Cuarta según se mire ${ }^{7}$ y parece que la reivindicación por la igualdad aparece como una exigencia justa y lógica ante la opinión pública. Ante esta emergencia feminista, los gobiernos y las empresas deben actuar por imperativo social.

Son los ambientes revolucionarios los que han sido favorables al avance social. En momentos históricos de controversia, en medio de entornos convulsos, es cuando aparecen las preguntas que promueven los cambios. Son épocas socialmente anómalas en las que se produce una fisura en el entramado societal, una brecha positiva por la que entra un poco de espíritu libre e igualitario. Por esa grieta es por donde se cuela la ética para tratar de dar respuestas. Sociedad, estado y empresa, deben dialogar, cooperar en clave feminista a fin de esbozar un nuevo diseño social en perspectiva de género garante de la igualdad de género. De esta manera, la acción de la sociedad civil obliga a reaccionar a los gobiernos instando políticas de igualdad, y éstas a su vez, deben repercutir en decisiones empresariales paritarias. Pues, si los gobiernos refrendan las demandas sociales, las transformaciones impactarán en el imaginario empresarial y harán surgir nuevas ideas y mejores prácticas. Se trata de un asunto de corresponsabilidad y requiere voluntad de cambio de todos los agentes sociales.

Empecemos por la última variable: la empresa. Siguiendo la ética dialógica defendida por la Escuela de Valencia (VVAA, 1994), la realidad social es un

\footnotetext{
5 Consultar la totalidad del proceso en: https://www.eldiario.es/sociedad/Cronologia-denunciaviolacion-sentencia-provisional_0_832916986.html

${ }^{6}$ El caso Harvey Weinstein acabó destapando prácticas de abuso sexual en Hollywood: «Harvey Weinstein Paid Off Sexual Harassment Accusers for Decades». El hastag denuncia episodios de acoso en todos los espacios y ámbitos. Disponible en: https://www.nytimes.com/2017/10/05/us/harveyweinstein-harassment-allegations.html. \#Cuéntalo visibiliza las prácticas de acoso, abuso y agresión sexual: Consultar en htttps://www.eldiario.es/andalucia/enabierto/Cuentalo_6_768233191.html

7 «Debatir acerca de si se trata de la cuarta ola del feminismo o del final de la tercera, es un tema secundario. La cuestión es que algo está pasando» (S. REVERTER. «Emergència feminista», en la revista El Temps n ${ }^{\circ} 1760,2018$, pp.28-37. Disponible en: https://www.eltemps.cat/article/3503/ emergencia-feminista).
} 
paradigma de intereses complejo, en el que la empresa no es sino una institución cuya finalidad es la consecución de determinados bienes. Como agente social, cualquier empresa ha de cumplir con unas expectativas para legitimar su existencia de cara a la sociedad, pues en ella se entremezclan intereses que atañen a las capacidades humanas y a su entorno medioambiental. A partir de ahí se establece una especie de contrato moral $^{8}$ entre el mercado y la ciudadanía, un capital de confianza. Es esta responsabilidad moral la que insta a la empresa a promover y garantizar condiciones igualitarias de participación para los diferentes grupos implicados en su actividad, y en consecuencia, obliga a la inclusión de las mujeres en la toma de decisiones a la hora de crear consensos y llegar a acuerdos. Dadas las condiciones actuales, el Derecho del Trabajo ${ }^{9}$ en España, exige una revisión y reelaboración urgente de las dispensas vinculadas al término para que las mujeres puedan ejercer el derecho a la ciudadanía empresarial ${ }^{10}$.

Y es que la actual configuración del mercado de trabajo, y su carga cognitiva dista mucho de aquellas que se perfilaron a finales del siglo XIX. Aun así, pese al cambio que estamos experimentando, la consecución de una ciudadanía empresarial plena sigue siendo utópica en nuestro tiempo, pues heredamos el modelo empresarial desarrollado en el siglo XX. En él, se fomentaron los modelos del hombre proveedor y la mujer cuidadora. Esta división sexista de las competencias humanas limitó las posibilidades de trabajo de las mujeres, erradicó las condiciones de participación igualitaria en el mercado, y sobre todo construyó la identidad social de género. Una mochila que pervive de forma sistemática en nuestras construcciones sociales adscribiendo valores al género en todos los ámbitos. Como hijas de aquel "pecado original"11 que cometieron nuestras madres trabajadoras, el mercado en nuestra sociedad moderna no garantiza las mismas posibilidades para ellas y para ellos. La protección laboral por sexos no es neutra: margina y excluye, y la Patronal ${ }^{12}$ se resiste al cambio y sigue operando en prácticas rutinarias que distribuyen la carga de producción en función del sexo, y que, por encima de todo, jerarquizan el proceso de toma de decisiones. Con todo, nuestro mercado laboral discrimina en tanto que hay un grupo de sujetos que no se encuentra en igualdad de condiciones a la hora de ejercer sus derechos fundamentales, no desempeña el derecho a la ciudadanía empresarial.

\footnotetext{
${ }^{8}$ Entendido como la respuesta ética que como presunción deben asumir las empresas para con la sociedad, a fin de legitimar la pertenencia a su entorno y su legitimidad. D. GARCIA-MARZÁ. Ética Empresarial del diálogo a la confianza. Trotta: Madrid, 2004.

${ }^{9}$ El Derecho del Trabajo son las garantías laborales, deberes y derechos de la fuerza de trabajo. Reflejan las circunstancias sociales, culturales y económicas de cada momento histórico. E. CAAMAÑO. "Mujer y trabajo: Origen y ocaso del modelo del padre proveedor y la madre cuidadora". En Revista de Derecho de la Pontificia Universidad Católica de Valparaíso. XXXIV (Valparaíso, Chile, 1er Semestre de 2010, pp. 179-209).

${ }^{10}$ D. GARCÍA-MARZÁ. Ética Empresarial del diálogo a la confianza. Trotta: Madrid, 2004.

${ }^{11}$ Permítase la licencia metafórica del término.

${ }^{12}$ Entendida como la organización que agrupa a los empresarios de un país o territorio.
} 
Como parte de un proceso natural, la forma de entender el trabajo y las relaciones de género cambian al verse afectadas por la globalización y otros procesos (Abrano y Todaro, 1998). Por un lado, las nuevas realidades del mercado influyen en las políticas laborales y transforman la cadena productiva arraigada en el sistema sexo género. Por otro, las reivindicaciones feministas están ya en la agenda mundial ${ }^{13}$, y el pasado ocho de marzo de 2018, millones de mujeres y familias ${ }^{14}$ tomaron las calles para exigir la igualdad de género, lo que implica una nueva forma de entender el lugar de las mujeres en el mundo. Bajo el lema «si las mujeres paramos, se para el mundo» ${ }^{15}$, la Ola Feminista del $8 \mathrm{M}$ inundó las portadas de los principales medios internacionales, y según aportan sus informaciones, España se convirtió en el epicentro del tsunami feminista ${ }^{16}$.

Podemos especular acerca del éxito de la convocatoria en España en base al eco de movimientos internacionales como el \#MeToo que se difunden a través de las redes sociales, mecanismos que ya no pasan el filtro de los gatekeepers, tradicionalmente masculinizados. Sin embargo, la situación de las mujeres en España tiene algunas peculiaridades que tal vez sean las verdaderas causantes del éxito del 8M. Sin dejar al margen casos como el de La Manada, que han despertado el sentir colectivo de pertenencia, cabe destacar que ya en diciembre de 2014, la ONU visitó España para evaluar las políticas de igualdad y contra la violencia de género. En su informe, la ONU denunció que las mujeres fueron las más golpeadas durante la crisis, y que también sufrieron con más intensidad la reforma labora $1^{17}$. Cuatro años después, las mujeres salieron a la calle para decir "basta".

\footnotetext{
${ }^{13}$ Jessa Crispin señala que el feminismo contenía cargas peyorativas como pertenecer a una cultura marginal formada por grupos de activistas radicales, mujeres peculiares vistas como poco agraciadas físicamente que odiaban a los hombres (J. CRISPIN. Porqué no soy feminista. Los libros del lince: Barcelona, 2017). En la actualidad el término ha adquirido el significado que le dio Gloria Stein, icono de las movilizaciones norteamericanas en los años 70 y 80 . Ser feminista hoy es cualquier persona que reconozca la igualdad y la humanidad plena entre hombres y mujeres.

${ }^{14}$ Para profundizar en datos y cifras, consultar: https://www.publico.es/sociedad/manifestacion- $8 \mathrm{~m}$ madrid-8-m-feminismo-historia.html

${ }^{15}$ La huelga española imitó la de 1975 en Islandia. La idea surgió entonces de las feministas de Redstockings y su lema fue "Day Off". Apelaron a todas las mujeres sin distinción de ideología ni clase. Trataron de visibilizar que sin las mujeres no hay democracia. Logró un éxito arrollador. En esta ocasión, mujeres de 150 países estaban convocadas a una huelga total -en el trabajo y en la esfera doméstica- a fin de visibilizar la sobrecarga diaria. (J. SISINIO. Historia del feminismo. Los libros de la catarata: Madrid, 2012).

${ }^{16}$ The New York Times encabezó con una fotografía de las concentraciones de Bilbao; The Guardian destacó el gran seguimiento de la huelga feminista en España; Le Monde abrió con España el titular de su fotogalería; La $B B C$ informó sobre el seguimiento de la huelga española. «La primera huelga feminista en España, en los principales medios internacionales». Disponible en: https://politica.elpais. com/politica/2018/03/08/actualidad/1520528768_368042.html

${ }^{17} \mathrm{La}$ ONU advirtió que los recortes incidieron con mayor virulencia en los sectores feminizados como la sanidad, la educación y los servicios sociales; y denunció que las medidas del Gobierno para salir de la crisis se habían centrado en crear empleo masculino. Por último destacó la persistencia de la violencia de género, que denunció ser alarmante.
} 
No es casual que el $8 \mathrm{M}$ empezara siendo «el día de la mujer trabajadora» ${ }^{18}$ para devenir en «el día de la mujer», más inclusivo y universalista. De esta manera, lo que empezó siendo una reivindicación en el ámbito empresarial, volvió a la esfera personal para reivindicar el lugar de las mujeres como individuos. Así pues, hablar de ciudadanía empresarial y derecho al trabajo requiere empezar por el principio, por la mujer como sujeto, y redefinir el lugar de las mujeres pasa por empoderar a la mujer como ser capaz de desarrollar un proyecto de vida pleno. Con esto, podríamos estar refiriéndonos a la regulación de mecanismos legales y asistencias políticas que normalizaran la igualdad y garantizaran el bienestar de las mujeres en todas las esferas de la vida. Pero el bienestar no es suficiente, y cuando hablamos de redefinir el lugar de las mujeres no nos referimos a la manera de estar en el mundo -con sus circunstancias y sus particularidades contextuales- sino a la forma de ser en el mundo. Aspirar al bienser de las mujeres como fin en sí mismo va más allá de los condicionantes del entorno, pues responde a los problemas derivados del ser mujer en todo el planeta, problemas estructurales que requieren un enfoque universalista $\mathrm{e}$ inclusivo.

Ahora bien, como venimos repitiendo, lo personal es político y mercantil, y el bienser de las mujeres en el mundo debe proyectarse en todas las esferas. Desde estas páginas, proponemos que el engranaje de todo el entramado se consiga mediante la práctica del feminismo cooperativo, siendo entendido éste como una actitud proactiva hacia la consecución de la igualdad de género en todos los ámbitos, pues «la revolución será feminista o no será». Si hace años se hablaba de paliar las desigualdades con la inclusión de medidas en perspectiva de género, el feminismo cooperativo en clave dialógica, nos permite ensamblar sociedad, estado y mercado en un haz indisoluble para diseñar un nuevo proyecto de reingeniería social. Un entramado que coloque el bienser de las mujeres en el centro del debate, y cuyo objetivo sea el establecer un diálogo en clave hermenéutica que priorice la inclusión de las mujeres como valor en sí mismo. Proyectar este nuevo paradigma social es una cuestión de dignidad humana, y es un asunto urgente.

Empecemos demostrando el vínculo indisoluble que se establece entre lo mercantil, lo social y lo doméstico. A nivel individual, el bienestar de los ciudadanos se logra a través de la obtención de determinados bienes. Éstos se consiguen mediante los recursos obtenidos del mercado y del estado. Del mercado se obtienen los ingresos de los hogares, y del estado los sistemas de protección mediante las

\footnotetext{
${ }^{18}$ Alemania, Austria, Dinamarca y Suiza fueron los primeros países en celebrarlo en torno al 19 de marzo de 1911. El incendio de la fábrica de TriangleShirtwaist (25 de marzo de 1911, New York) prendió la llama del feminismo en EEUU. En 1914, Rusia declaró el 8 de marzo Día Internacional de la Mujer. Alemania y Suecia se adscribieron, igual que el resto de Europa. En 1975, las Naciones Unidas declararon el 8M como Día de la Mujer Trabajadora. En él se reivindica la igualdad de oportunidades en su desarrollo íntegro como persona.
} 
políticas sociales, que incluyen toda una serie de políticas públicas educativas y de asistencia. El ensamblaje de toda esta maquinaria de bienes materiales e inmateriales se produce en la esfera doméstica ${ }^{19}$, y es en el espacio privado donde empieza a pervertirse la igualdad de género. Este vínculo indisoluble entre lo mercantil, lo social y lo doméstico se demostró en la crisis del 2013, que afectó a las empresas y a los estados en general, y a la mujer en particular.

A saber, desde finales de los noventa del pasado siglo, y principios del nuevo milenio, el sistema de mercado vigente, el capitalismo, se camufló en el llamado Estado del Bienestar. En él, los gobiernos promovieron políticas sociales que repercutieron en unos niveles de justicia aceptables para la ciudadanía en general. Sin embargo, cuando el capitalismo entendió que las actuaciones sociales lastraban al sistema económico, su ansia de libertad convenció al estado para justificar el fin del intervencionismo estatal y la liberalización del mercado. Con esto, el Estado del Bienestar fracasó y el bienestar de las mujeres, en particular, se hundió con él. Para la profesora Adela Cortina, la causa del primer derrumbe fue la confusión entre bienestar y justicia: el Estado del Bienestar hubiese tenido que orientar sus políticas hacia la consecución de un Estado de Justicia ${ }^{20}$. Esto es, asentar una serie de mecanismos garantes de la justicia social y no legitimados únicamente en el bienestar económico y material, ya que la economía no abarca todas las esferas vitales del ser humano. El segundo hundimiento, el de las mujeres, llegó con forma de políticas de austeridad que además de los recortes y la destrucción de empleo, reforzó el modelo familiarista $^{21}, \tan$ practicado por nuestras abuelas.

Con todo y con eso, no cabe duda de que la primera consecuencia que se desprende es que, cuando los gobiernos miden el bienestar de la ciudadanía en parámetros económicos, queda al descubierto la fragilidad del vínculo entre bienestar y justicia. La segunda consecuencia es que «el sistema capitalista tiene como uno de sus fundamentos la pervivencia del patriarcado» $\rangle^{22}$, en otras palabras, cuando el sistema se hunde, el capitalismo es el encargado de poner a las mujeres en su sitio para ejercer las labores de asistencia y de cuidado propias de su género.

\footnotetext{
${ }^{19}$ A. SOJO. "Estado, mercado y familia: el haz del bienestar social como objeto de política". En CEPALSERIE Seminarios y conferencias. 2005, № 46, pp. 149-161. Consultar en https://repositorio.cepal.org/ handle/11362/6809.

${ }^{20}$ La idea del bienestar es para Adela Cortina un ideal de la imaginación y no de la razón, puesto que cada ciudadano imagina su bienestar como la satisfacción de todos sus deseos y ningún Estado sería capaz de satisfacerlos. Es imposible, porque son infinitos, y optaría por los que proporcionan votos y no por los que representan exigencias básicas de justicia (A. CORTINA. Por una ética del consumo. La ciudadania del consumidor en un mundo global, Taurus: Madrid, 2002).

${ }^{21}$ Carmen Castro define así las políticas ocultas de privatización de los cuidados, en las que el Estado espera que se cubran las necesidades de las personas dependientes mediante la solidaridad familiar (C. CASTRO. Políticas para la igualdad. La catarata: Madrid, 2017).

${ }^{22}$ S. REVERTER. «Emergència feminista», en la revista El Temps nº1760, 2018, pp.28-37. Disponible en: https://www.eltemps.cat/article/3503/emergencia-feminista.
} 
Así las cosas, rediseñar un entramado social más justo, inclusivo y universalista pasa por disociar bienestar y economía. En la actualidad, la mayoría de mediciones de la calidad de vida están implícitamente asociadas a una teoría normativa de la maximización (del salario, de la utilidad, del beneficio). Este es el caso del PIB, o la renta per cápita. Pero, ¿qué validez tienen los índices de desarrollo del informe PNUD en países en los que continuamente se violan los Derechos Humanos? ${ }^{23} \mathrm{El}$ Nobel de Economía AmartyaSen, se distancia de este tipo de mediciones y aboga por la inclusión de todos los aspectos posibles de la realidad a la hora de hablar de economía ${ }^{24}$. Por su parte, Martha Nussbaum propone considerar un mínimo de cada capacidad por debajo de la cual no se considera posible que los ciudadanos puedan lograr un funcionamiento verdaderamente humano ${ }^{25}$. Lamentablemente, como hemos visto con el caso de la crisis económica, a menudo se trata a las mujeres como un medio para lograr algo, y no como fin. De esta manera, las mujeres sufren, de forma generalizada, una aguda falta de capacidad para desarrollar sus proyectos de vida plena. Esto nos lleva a que la agencia de las mujeres es una cuestión de justicia internacional para los Derechos Humanos, y de ella depende el desarrollo económico de las naciones, ya que se está desperdiciando la mitad del potencial humano del planeta.

Es la justicia la que conlleva al bienestar, y no la economía. Además, se trata de una emergencia ya que es urgente focalizar la cuestión de las mujeres como eje del nuevo entramado social de plena igualdad. Lo personal es político y mercantil reivindica la desigualdad que empieza en casa, sigue en la sociedad, y acaba en la empresa. Este desequilibrio en el desarrollo de las capacidades humanas, que afectan al bienser de las mujeres, responde a razones estructurales que requieren un trato universalista. El feminismo cooperativo aboga por el diálogo entre sociedad, estado y mercado con el fin de lograr un cambio en el lugar que ocupan las mujeres en el entramado social vigente. Tras las movilizaciones del $8 \mathrm{M}$, ahora sabemos que si no dialogan, la ciudadanía les obligará a hacerlo.

\footnotetext{
${ }^{23}$ Sirvan de ejemplo los Emiratos Árabes Unidos, con una renta per cápita de 40.200 dólares y un considerable superávit anual. Sin embargo, los trabajadores extranjeros sufren explotación laboral y malas condiciones de vida. Al igual que las mujeres, que siguen siendo discriminadas como sujetos ante la ley. (Amnistía Internacional, 2011) «Emiratos Árabes pendientes de los derechos de las mujeres e inmigrantes». https://elpais.com/internacional/2011/02/28/actualidad/1298847609_850215. html. Ser miembro de un país en desarrollo tampoco es sinónimo de prosperidad humana, dignidad ni empoderamiento femenino. Desde la crisis, en España se ha revelado un aumento en la exclusión social, su modelo de desarrollo económico sólo genera desigualdad, y está transformando el "contrato social" en un "contrato mercantil". Consultar en: http://www.foessa2014.es/informe/uploaded/descargas/VII_INFORME.pdf

${ }^{24} \mathrm{El}$ enfoque de las capacidades (Sen, 2000) remite a aquello que el ser humano es capaz de hacer y ser. Es un enfoque universal, pues se basa en el principio fundamental de que toda persona debe ser considerada como un fin, en todas las naciones, en ambos géneros.

${ }^{25}$ Nussbaum denomina a este requisito mínimo social básico al mínimo requerido para el respeto por la dignidad humana. Su objetivo es desarrollar una nueva Teoría de la Justicia mediante unos principios respetados por los gobiernos de todas las naciones (M. NUSSBAUM. Las mujeres y el desarrollo humano. Herder: Barcelona, 2002).
} 


\section{Sociologia de género: érase una vez el lastre del patriarcado}

En el primer canto de la Odisea, Penélope expresa un mandato a su hijo Telémaco, y éste, en resumen, la manda callar de la siguiente forma: "Madre, entra en casa y ocúpate de tus labores, el telar y la rueca [...] el relato estará a cargo de los hombres. Mío es el gobierno de la casa" ${ }^{26}$. El ser humano es un constructo narrativo, para vivir tenemos que narrarnos. La existencia se basa en un conjunto de creencias más que de vivencias porque la memoria es débil y traidora, así que muchas veces tan sólo somos producto de nuestra imaginación, o de la de los demás. De esta manera, la identidad es algo ficcional, es un relato ${ }^{27}$. Y eso es bueno, porque significa que se puede cambiar.

Durante siglos, la dominación masculina del relato ha aislado a las mujeres del control del discurso público, confinándolas en el hogar. Sin embargo, esto las convirtió en mujeres estoicas que sustentaron el mundo, y que siguen siendo los verdaderos pilares de la tierra. Aun así, pese a ser las verdaderas protagonistas, su falta de capacidades para reescribir la historia, no les ha deparado un final feliz. Cuando decimos que el mundo cabalga a los hombros de las mujeres nos referimos a que, en la mayoría de las ocasiones, ellas son las encargadas de la transmisión de los valores culturales a través de la crianza de los hijos. Son las reproductoras de ese sistema sexo-género que imitamos desde la infancia a través de un sutil y constante proceso de socialización, y que luego, reproducimos en la edad adulta de forma sistemática ${ }^{28}$. De esta manera, los roles asociados al género se infunden desde la esfera doméstica -los traemos puestos de casa-, y en algunas ocasiones, no es descabellado afirmar que son las propias mujeres las encargadas de educar en determinadas prácticas machistas, puesto que, tal vez sin saberlo, siguen encadenadas a la reproducción cultural aprendida durante siglos. Estas prácticas se difunden en todas las esferas vitales: políticas y empresariales. Y la historia acaba así en todas las culturas del mundo, por los siglos de los siglos. Es por esto que decimos que la desigualdad de género no es contextual sino estructural, porque no depende de una situación, sino que es sistémica. Y es por esto que decimos también que, si bien todas y todos somos machistas por herencia cultural - aunque nos pese reconocerlo -, también todos y todas deberíamos ser feministas: por imperativo moral y por legado social.

\footnotetext{
${ }^{26}$ M. BERAD. Mujeres y poder: un manifiesto. Crítica: Barcelona, 2018.

${ }^{27} \mathrm{La}$ estructura social se basa en la imaginación como medio de cohesión social. El imaginario social que la conforma su entramado es un relato que se inicia en literatura y se vivencia en las prácticas sociales y políticas diarias. (C. ALMONACID. "El poder de la imaginación, de la ficción a la acción política. Ideología, y utopía en la perspectiva de Paul Ricoeur", Recerca, Revista de Pensament $i$ Anàlisi, n²2, 2018, pp. 153-172. Disponible en: http://www.e-revistes.uji.es/index.php/recerca/article/ view/2351/2705).

${ }^{28}$ Las mujeres son el puente entre la naturaleza y la cultura: trasbasan a la persona desde la infancia hasta la persona adulta. Vandana y Mies (2016) sintetiza todo este proceso como producción de la vida (S. VANDANA y M. MIES. Ecofeminismo. Icaria: Barcelona, 2016).
} 
En un apunte rápido de feminismo, el eje básico de la discriminación se basa en los roles interiorizados que separan la esfera pública y productiva del hombre, de la privada y reproductiva de la mujer -no solo en sentido biológico, sino también en lo que a pautas de conducta y expectativas sociales se refiere-. Esta división ${ }^{29}$ social de los individuos provoca la reclusión-exclusión de las mujeres en el hogar, y explica la subordinación de la hembra al varón en el orden social como algo natural. Pese a que, paradójicamente, la labor reproductiva de la madre cuidadora es en realidad la base del trabajo del padre productor, las labores de crianza y cuidado no se consideran como tal, puesto que además, no suponen ningún aporte económico al núcleo familiar.

En su obra De animales a dioses, el historiador israelí Yuval Noah Harari ${ }^{30}$, dedica varios capítulos a la jerarquía de género. Sin embargo, a sabiendas de que en todas las culturas se ha entronizado la superioridad masculina, no encuentra razones ni respuestas convincentes para explicar el porqué. Lo que sí reconoce es que en el siglo XX se ha empezado a reescribir la historia porque tras una superioridad masculina durante milenios, la revolución de los papeles de género ya es, en sí misma, un hito de la humanidad. Así que ha llegado el momento de cambiar el final, o mejor, de empezar una nueva historia porque si bien decíamos que la desigualdad de género es estructural, ahora sabemos que el empoderamiento femenino también lo está siendo.

Mujeres poderosas han existido desde siempre. Tenemos mujeres del Norte y del Sur, de Oriente y Occidente, de países desarrollados y en desarrollo -poco importan las nomenclaturas. Están en todas partes aquellas que tienen el poder de cargar con la doble jornada ${ }^{31}$, las que luchan por un trabajo en inferioridad de condiciones -con discriminación salarial, la intimidación de la familia, del esposo o la sociedad, el acoso sexual... También las hay quienes se dedican a cuidar de los más necesitados con el trabajo sin pagar de la crianza de los hijos ${ }^{32}$, a los ancianos y a los dependientes. Éstas son tan poderosas, que han logrado que se las atribuya la Ética del Cuidado ${ }^{33}$, hasta el punto que podemos hablar de trabajos feminizados

\footnotetext{
En su lógica del patriarcado, Carol Pateman expone que debido a esta división social normalizada, el espacio público del hombre se asocia al poder, la política, la cultura, el intelecto, el éxito, la razón... Mientras que a la mujer se le atribuye el mundo de lo personal y privado, la naturaleza, lo emocional, la intuición, el amor y el cuidado... De esta forma, los hombres construyen el relato del mundo controlando la cultura, el mercado y el estado (C. PATEMAN. El contrato sexual. Anthropos: Barcelona, 1995).

${ }^{30}$ Y. N. HARARI. De animales a dioses. Debate: Barcelona, 2014.

${ }^{31}$ N. FRASER. “¿Qué tiene de crítica la Teoría Crítica? Habermas y la cuestión del género”. En Teoría Feminista y Teoría Crítica. EdicionsAlfons el Magnànim: València, 1990, pp. 49-87.

${ }^{32}$ N. FRASER. “¿Qué tiene de crítica la Teoría Crítica?.., pp. 49-87.

${ }^{33}$ Para Gilligan, el rol de la mujer en La ética del cuidado asume unos presupuestos que han sido "culturalmente" aprendidos y asignados al género femenino. En su tercera fase, Carol Gilligan defiende que tanto mujeres como hombres somos autónomos en cuanto a ser capaces de cuidar de nosotros
} 
o sexualizados como la sanidad, la educación y los servicios sociales. Unas deben trabajar a media jornada para cuidar de todo lo demás, y otras directamente en la economía sumergida, que las invisibiliza ante cualquier inspección o forma de normalización. Y todo esto solo pasa en el mejor de los casos.

En la mayor parte del mundo, las mujeres carecen de apoyo en funciones fundamentales de la vida humana ${ }^{34}$. Están peor alimentadas que los hombres, tienen un nivel inferior de salud, son más vulnerables a la violencia física, y con toda probabilidad carecen de instrucción básica, mucho menos profesional o técnica. Tampoco poseen recursos legales efectivos para defenderse ni tan siquiera la plena potestad para poder participar de forma efectiva en la política. En muchas naciones ${ }^{35}$ las mujeres no tienen igualdad ante la ley: no tienen los mismos derechos de propiedad que los hombres, ni los mismos derechos contractuales, de movilidad, ni tan siquiera de libertad religiosa. Tienen menos oportunidades que los hombres de vivir libres de temores y de disfrutar de formas más gratificantes de amor: mutilados sus genitales, violadas con total impunidad en algunos países $^{36}$, y especialmente vilipendiadas

mismos y de los demás (C. GILLIGAN. Daño moral y la ética del cuidado. Cuadernos de la Fundació Víctor Grífols i Lucas La ética del cuidado: Barcelona, № 30, 2013).

${ }^{34}$ Las funciones fundamentales para ejercer el derecho a una vida digna de ser vivida pasan por garantizar leyes y mecanismos que protejan a las mujeres y las igualen en paridad de condiciones a los varones, así como potencializar un marco de posibilidades que les permita desarrollar todas sus capacidades. Del informe PNUD (Programa de las Naciones Unidas para el desarrollo encargado de evaluar parámetros combinatorios referentes a la expectativa de vida, la riqueza y la educación) de 2015 se extrae que si bien son un total de 195 conformantes: 49 de ellos, no tienen leyes que protejan a las mujeres de la violencia de género (de hecho, sólo 107 disponen de datos sobre la violencia doméstica); en 32, los procedimientos para obtener un pasaporte difieren de los de los hombres; en 18 países, las mujeres necesitan la aprobación de su marido para aceptar un trabajo. Si hablamos del matrimonio infantil en los países con bajo nivel de desarrollo humano, el 39 por ciento se casaron antes de cumplir 18 años. Además, el PNUD 2015, muestra que realizan la mayor parte del trabajo global (un 52\%), pero afrontan desventajas tanto en el trabajo remunerado como en el no remunerado. Además, realizan tres veces más trabajo no remunerado que los hombres (un 31 por ciento versus un 10 por ciento) y, cuando su trabajo es remunerado, ganan un 24 por ciento menos que los hombres. Para mayor información acerca de los países en concreto: https://www.undp.org/content/undp/es/home/librarypage/hdr/2015human-development-report.html.

${ }^{35}$ El Índice de Brecha Global de Género del Foro Económico Mundial, estudia la paridad entre hombres y mujeres en base a la participación económica y de oportunidades, la educación, la participación política y toma de decisiones, y la salud y supervivencia. En su informe de 2018, detalla que, de los 142 países que lo conforman, Islandia, Finlandia y Noruega están en los primeros puestos, por su parte, Chad, Pakistán y Yemen, son los países en los que existen mayores diferencias entre hombres y mujeres. Disponible en: https://www.weforum.org/reports/the-global-gender-gap-report-2018.

${ }^{36}$ En 2018, la fundación Thompson Reuters realizó un estudio acerca de los países más seguros para las mujeres. De los 193 participantes, India se posiciona como el más peligroso en cuanto a violencia sexual, el trabajo doméstico forzado, la esclavitud sexual y el matrimonio forzado. El informe pone de relieve el elevado número de violaciones a menores, las tradiciones culturales como la mutilación genital, el matrimonio infantil o los ataques con ácido por rechazar a los pretendientes que les imponen sus familias o como castigo por una presunta desobediencia o infidelidad. Según datos de la Oficina Nacional de Registro Criminales de India, la policía recibe alrededor de 100 denuncias por agresiones sexuales cada día, a las que hay que sumar otras muchas más que quedan circunscritas en el ámbito 
cuando se les casa desde la niñez, a menudo sin capacidad de elección, arrastrando durante toda una vida las consecuencias de un mal matrimonio ${ }^{37}$. Y a todo esto cabría sumar, o restar, a las mujeres faltantes ${ }^{38}$. Por todo y por tanto, aquellas que logran sobrevivir, demuestran al mundo lo que es tener verdadero poder.

Las mujeres han tenido poder desde siempre, sí, pero ahora la percepción sobre el lugar de las mujeres en el mundo ha cambiado: se están empoderando. Así lo indican los datos del informe Gallup ${ }^{39}$. Y lo sorprendente es que cuentan con un aliado inesperado: los hombres.

Según el informe, el $70 \%$ de las mujeres a escala mundial preferiría estar trabajando, y los hombres están de acuerdo en un 66\%, incluso en varias regiones de Estados árabes. Además, en la mayoría de regiones del mundo, ambos sexos piensan que es aceptable que las mujeres de su familia tengan trabajo remunerado fuera del hogar si lo desean, hasta en África Septentrional ${ }^{40}$. En caso de tenerlo, las mujeres dicen que su salario es una fuente importante de ingresos para las familias, aunque los hombres siguen afirmando que ellos son el sostén del hogar. Este patrón se mantiene en cada parte del mundo salvo en Asia Oriental ${ }^{41}$. Según el informe, la brecha salarial se estrecha a mayor aumento del nivel de estudios. A este respecto, los hombres y las

familiar que nunca llegan a denunciarse. Solo en 2016 se reportaron 39.000 violaciones en el país, un $12 \%$ más que el año anterior. En segundo lugar se encuentra Afganistán, peligroso en cuanto al acceso a la atención médica y los recursos económicos, la violencia no sexual, relacionada con los conflictos y el abuso doméstico. Le sigue Siria, considerado el segundo más peligroso en términos de violencia sexual y acceso a la atención médica. Especialmente relevante destaca la décima posición perteneciente a los EEUU. Disponible en: https://blogs.publico.es/strambotic/2018/06/paises-para-no-ser-mujer/

${ }^{37}$ En algunas zonas del planeta como la China rural, la India, o las regiones islámicas en desarrollo, a las mujeres se les reserva un papel puramente demográfico como "reproductoras" sometidas, como ocurrió en occidente durante siglos. Las múltiples formas de dominación en sus circunstancias sociales y políticas, dan a estas mujeres capacidades humanas desiguales (MC. ROVIRA I ZARZOSO. Planeta finito: Superpoblación y feminismo. Una propuesta universalista de fundamentación ecologista para salvar el Planeta. Universitat Jaume I., 2015. Disponible en: http://hdl.handle.net/10234/147408). Cabe destacar que para autoras como Marta Nussbaum, la desigualdad de sexos está en fuerte correlación con la pobreza, como se desprende de su libro Las Mujeres y Desarrollo Humano (Nussbaum, 2002).

${ }^{38}$ Amartya Sen acuñó el término en 1998. Siguiendo a Sen, Nussbaum afirma que el número de mujeres faltantes en el sudeste asiático es de 2,4 millones; en Latinoamérica, 4,4; en el norte de África, 2,4; en Irán, 1,4; en China, 44; en Bangla Desh, 3,7; en la India, 36,7; en Pakistán, 5,2; en el oeste de Asia, 4,3. Recordemos que estamos hablando de millones (M. NUSSBAUM. Las mujeres y el desarrollo humano. Herder: Barcelona, 2002.).

${ }^{39}$ La Organización Internacional del Trabajo confió en Gallup para investigar acerca de las perspectivas laborales de las mujeres en el mundo. El informe publica de forma detallada los resultados de las encuestas realizadas en 2016 a 149.000 personas de 142 países y territorios (OIT. Avance global sobre las tenencias del empleo femenino. Oficina Internacional del Trabajo: Ginebra, 2018).

${ }^{40}$ Así lo opinan el 79\% las mujeres, y los hombres en un 57\%. Gallup destaca el peso de la familia en la toma de decisiones. En las regiones en que no es aceptable que las mujeres trabajen fuera del hogar, el $61 \%$ preferiría no hacerlo. Aun así, al 36\% si les gustaría.

${ }^{41}$ Allí las mujeres que trabajan, el 61\%, afirman que su contribución es ínfima. 
mujeres de todo el mundo afirman que, con un mismo nivel de estudios, se debería tener las mismas oportunidades laborales. Sin embargo, cabe destacar que, cuanto mayor es el nivel de estudios de las mujeres, piensan que no tendrán las mismas oportunidades que ellos a pesar de tener las mismas calificaciones ${ }^{42}$.

Por último, Gallup demuestra que la "conciliación de la vida laboral y familiar" se menciona como uno de los principales desafíos a los que se enfrentan las mujeres en todo el mundo. Y salvo excepciones, los hombres lo reconocen también. La conciliación es pues el mayor reto en los países emergentes y desarrollados. Por su parte, en las regiones en desarrollo lo que más preocupa es el trato laboral desigual; la falta de servicios de asistencia y del cuidado preocupa más en los países emergentes, y no tanto en las regiones desarrolladas, cuyo principal problema es la brecha salarial.

Con todo, parece ser que las actitudes de las mujeres y de los hombres no distan tanto a como apuntan las creencias tradicionales. Y parece ser también que el bienser de la mujer pasa por garantizar políticas educativas y de conciliación que permitan a las mujeres florecer en todas sus capacidades para desarrollar un proyecto de vida pleno. Respecto a lo primero, el lugar de las mujeres no es lo único que parece que se está redefiniendo. A nivel social existe un movimiento de hombres incómodos con el papel que les ha reservado la historia. Son inconformistas del patriarcado y apelan a renunciar a sus privilegios. Es el caso de Octavio Salazar ${ }^{43}$, quien explica que desde la infancia, familiares, amigos y conocidos insisten en reforzar la masculinidad. Un modelo hegemónico con la que muchos jóvenes hoy en día no se sienten cómodos. Salazar insiste en que, para avanzar, hay que destronar al macho de los privilegios del patriarcado, lo que Jonh Stuart Mill denominó la ideología del privilegio ${ }^{44}$. En este sentido, Joan Sanfèlix insiste en reeducar desde la infancia ${ }^{45}$. Sin embargo, no todos los hombres están dispuestos a aceptar la transición hacia una sociedad más igualitaria. Como señala el postmachismo ${ }^{46}$, muchos sufren

\footnotetext{
${ }^{42}$ GALLUP, OIT. Hacia un futuro mejor para las mujeres en el trabajo: la opinión de las mujeres y los hombres. 2018. Disponible en: http://www.ilo.org/wcmsp5/groups/public/---dgreports/---gender/ documents/publication/wcms_602066.pdf.

${ }^{43}$ Octavio Salazar es profesor de Derecho Constitucional en la Universidad de Córdoba y miembro de la Red Feminista de Derecho Constitucional. Su libro El hombre que no deberíamos ser es un manual destinado a los hombres feministas como él (O. SALAZAR. El hombre que no deberíamos ser. Planeta: Barcelona, 2018).

${ }^{44}$ Mill plantea la desigualdad que subyace en el hecho de que, por el mero hecho de haber nacido niño,un sujeto se considere superior a todos y cada uno de los miembros de la mitad de la raza humana. ${ }^{45}$ Sanfèlix es profesor de Sociología de la Universidad Jaume I y fundador de Hombres valencianos por la igualdad. Explica que cuando los niños juegan al fútbol ocupan casi la totalidad del patio de recreo, relegando al margen a las niñas y niños que no les gusta el fútbol o que no juegan bien.

46 Miguel Lorente, ex secretario de Estado contra la violencia machista señala que muchos hombres se sienten atacados por la pérdida de los privilegios. Argumentan que las medidas son desigualitarias para ellos, y siembran la duda alegando casos de denuncias falsas, mujeres que pegan a sus maridos.
} 
una crisis de identidad que les lleva a reafirmar el cuerpo como último reducto de la virilidad, y la apropiación del cuerpo de las mujeres sería otro de los síntomas, del que derivaría la violencia machista y las violaciones colectivas ${ }^{47}$.

Este es el lastre del patriarcado, la historia de queremos reescribir. A nivel social, las mujeres y los hombres se han pronunciado y han salido a las calles a gritar basta. Ahora es el momento de que los gobiernos actúen y tomen medidas educativas y de conciliación laboral, pero esto lo dejaremos para el siguiente apartado.

\section{Estado y género: coeducación y conciliación}

En una mayor profundización, y según se desprende del Informe Gallup, dos de los indicadores más relevantes en relación a la calidad de vida de las mujeres son la formación recibida y la conciliación laboral. La educación de la mujer incide en sus opciones de vida, y éstas se basan, principalmente, en los proyectos profesionales y familiares. Diseñar políticas coeducativas explícitas, y establecer mecanismos de servicio asistencial, sería un buen comienzo para que los gobiernos empezaran a hacer efectivo el mainstreaming ${ }^{48}$.

La escuela ha existido en todas las civilizaciones: erige los referentes históricos, difunde el conocimiento y crea identidades. Es más, a través de la ella, asumimos la responsabilidad de garantizar la continuidad del mundo. Pero si la educación es fragmentada, el proceso de socialización se verá truncado por la carencia de recursos, y el resultado será toda una cadena de consecuencias que dificultarán la comprensión global y dinamizadora de los fenómenos sociológicos, y lo que es peor, negarán la necesaria transformación social. Bien es cierto que, la transmisión cultural es necesaria porque venimos a un mundo que ya existe y que otros nos han contado, pero el siglo XXI nos plantea nuevos retos de gobernanza mundial y requiere de nuevos relatos. La educación pues ha de desafiar al saber conocido, dudar de lo aprendido hasta ahora.

Aducen que la igualdad no existe por definición biológica-científica, y atacan y desacreditan al feminismo tachándolo de doctrinario o moda pasajera. Para Lorente, solo son machistas camuflados (M. LORENTE. «Posmachismo cómplice», disponible en: https:/elpais.com/elpais/2017/11/22/ opinion/1511366105_861002.html).

47 En este sentido, en casos como en los de la manada, lo que hacen es un castigo a la desobediencia, una forma desesperada de reivindicar la masculinidad. Una fratría masculina que se revuelve contra su propia extinción (J. SANFÈLIX. «Las nuevas masculinidades. Los hombres frente al cambio en las mujeres». En Revista Social Prisma, nº7: Feminidades y Masculinidades, 2011, pp. 220-247. Disponible en: http://www.redalyc.org/html/3537/353744579008/).

${ }^{48}$ La Unión Europea estableció el Mainstreamingen 1999 como estrategia política a favor de la igualdad de género en todos los ámbitos, niveles, etapas y ámbitos de la vida, a fin de combatir el sistema patriarcal de forma explícita, y lograr la inclusión de la perspectiva de género en la agenda de gobernanza política. En ella, se destaca la inclusión en procesos deliberativos de expertos en igualdad de género. LOMBARDO, 2003 consultado en https://app.sernam.cl/pmg/archivos_2007/pdf/Art_ MainstreamingUE.pdf 
La genealogía del conocimiento femenino ha revelado que la contribución de las mujeres al desarrollo humano y a la construcción del conocimiento se ha dado de forma continuada desde la Antigüedad. Sin embargo, la construcción patriarcal del saber ha invisibilizado a las mujeres, con lo que ha prescindido de la mitad de la Humanidad ${ }^{49}$. Este déficit académico supone un relato falto de rigor, excluyente y androcéntrico. Y este discurso está presente en todos los ámbitos de la sociedad, la política y la empresa. Es el sustrato sobre el que se asienta nuestra realidad y nuestra forma de verla. Nos guste o no, todos y todas somos machistas de nacimiento a falta de una educación en perspectiva de género ${ }^{50}$. Pero no bastaría con incluir la asignatura de feminismo en el currículo, la perspectiva de género debería ser transversal a todas las materias y etapas. Hablamos de cambiar los contenidos curriculares, crear nuevos itinerarios, modificar el sentido y la perspectiva del mundo en clave feminista, formar al profesorado en género, eliminar las prácticas machistas en el lenguaje y en el uso de los espacios... En definitiva, llevar a término las prácticas de la coeducación ${ }^{51}$. Se educa para el futuro, porque educar es «guiar al que empieza a vivir, en esta su marcha responsable a través del tiempo» ${ }^{52}$. En definitiva, educar es preparar para la libertad. Sin embargo, de poco sirven las alas cuando el horizonte es finito y volar se hace imposible más allá del techo de cristal ${ }^{53}$.

No deja de ser curioso el hecho de que la falta de mujeres en los libros de texto contrasta con el número de mujeres en las aulas. Pese a todo, sigue habiendo pocas rectoras para tantas universitarias. A saber, en España, las mujeres se matriculan más mujeres (el 54\%) que hombres, y las cifran indican que son más aplicadas que ellos (el 57\% se gradúa). Sin embargo, al llegar al doctorado, las cifras se igualan $(50 \%)$. Es aquí donde empieza la desigualdad que determina que sólo cuatro mujeres sean rectoras de las cincuenta universidades públicas del país ${ }^{54}$. La causa es sencilla: lograr una actividad académica consolidada necesita dedicación, y cuando llega el

\footnotetext{
${ }^{49}$ En los libros de texto de la ESO (Educación Secundaria Obligatoria) solo el $12 \%$ \% son mujeres, y su ausencia aumenta a mayor nivel de la ESO. Los desajustes se producen en el lenguaje y en los contenidos. En los 80 se afianzaron los estereotipos del lenguaje, y en el 2000 se produjo una mejoría, aunque el abuso de genéricos siguió ocultando a la mujer. Desde los 80 , la presencia de las mujeres en los textos apenas ha aumentado. (A. LOPEZ-NAVAJAS. Análisis de la ausencia de las mujeres en los manuales de la ESO: una genealogía ocultada. Revista de Educación, 363, enero-abril 2014. Proyecto TRACE desarrollado por la Universidad de Valencia y el Ministerio de Igualdad. Disponible en: http:// www.revistaeducacion.mec.es/doi/363_188.pdf).

${ }^{50}$ No faltan las voces que exigen formación en materia de género de todos los agentes sociales, en concreto de los operadores jurídicos encargados de legislar y sentenciar. En el informe de 2014, la ONU ya alertó a España de la necesidad de formar en género a los juristas.

${ }^{51}$ Propuesta normativa que pretende superar el modelo de la escuela mixta -reproductora del sistema patriarcal. Su objetivo es capacitar individuos con proyectos de vida propios, formar personas que de forma libre, autónoma y carente de prejuicios, decidan qué ser, y cómo.

${ }_{52}$ M. ZAMBRANO. Filosofía y educación (manuscritos). Editorial Club universitario: San Vicente (Alicante), 2011. https://www.editorial-club-universitario.es/pdf/4399.pdf

${ }^{53}$ Limitación velada del ascenso laboral de las mujeres.

54 «Pocas rectoras para una mayoría de universitarias», disponible en: https://politica.elpais.com/ politica/2018/03/04/actualidad/1520195159_462681.html
} 
momento de investigar y publicar, toca optar por la maternidad o por ascender. Es lo que se conoce como techo de cristal, y la realidad académica sólo es un ejemplo de empresa que, como cualquier otra, no es sino un reflejo de las estructuras sociales más profundas.

Equilibrar trabajo y familia es la clave del desarrollo social y económico de las naciones. Establecer las medidas de conciliación requiere de procesos deliberativos de negociación colectiva entre todos los agentes sociales implicados. El marco normativo de la ética dialógica en clave feminista garantiza los mecanismos necesarios para articular el debate y legitimar el consenso. Parece algo fácil, pero la realidad es que, en la praxis, la conciliación entre el estado y la familia tampoco ha sido un asunto sencillo.

A saber, en los años 60, los gobiernos se desentendían de las políticas públicas al considerarlo como algo secundario e improductivo a nivel económico. Es a partir de la década de los 80 cuando se debate la construcción del género y se relaciona con la separación entre lo público y lo privado. Pero al ser la familia algo del ámbito privado, el asunto del género se despolitizó, y así se agrandó la brecha entre hombres y mujeres en base a las diferencias naturales, roles sociales, funciones matrimoniales, estereotipos sexuales, planes educativos. Y cuanto más se incorporaba la mujer al mercado laboral, más se agrandaban las diferencias, porque el trabajo doméstico seguía siendo cosa de mujeres. Fue entonces cuando las responsabilidades familiares y la maternidad comenzaron a ser un verdadero problema.

En algunos países, la baja natalidad no llegaba ni a la tasa de reposición ${ }^{55}$ con lo que se puso en jaque la financiación de los sistemas de protección social, y la figura de la housewifery a doble jornada - pilar del bienestar- entró en peligro de extinción. Eran mediados de los 90, y algunos países de la Unión Europea establecieron estrategias de ajuste que tomaron la vía tradicional de la compatibilización - que no conciliación - de las tareas adscritas a las mujeres ${ }^{56}$. Pero la insatisfacción continuó, y la igualdad de género siguió sin ser efectiva. A finales de los 90 , las teorías feministas empezaron a polemizar con lo que había sido conceptuado el estado del bienestar (que asociaron mujer y políticas sociales) y tras la crisis iniciada en 2008, las mujeres volvimos a la casilla de salida: el modelo familiarista.

\footnotetext{
${ }^{55}$ La tasa de fertilidad en Occidente es, desde hace casi treinta años, inferior a 2,1 En Europa la tasa de fertilidad femenina es inferior a 2; en España e Italia está por debajo del 1,5 con mínimos entre 1,1 y 1,2 (MC. ROVIRA I ZARZOSO. Planeta finito: Superpoblación y feminismo. Una propuesta universalista de fundamentación ecologista para salvar el Planeta. Universitat Jaume I, 2015. Disponible en: http:// hdl.handle.net/10234/147408).

${ }^{56}$ Algunas de las consecuencias fueron: la reducción de objetivos (renunciar a los ascensos y a la excelencia doméstica); la adquisición de servicios privados de guarderías, residencias de ancianos, asistentes domiciliarios; discontinuidades laborales con excedencias y permisos (A. SOJO. "Estado, mercado y familia: el haz del bienestar social como objeto de política". En CEPAL-SERIE Seminarios y conferencias. 2005, $\mathrm{N}^{\circ} 46$, pp. 149-161. Consultar en https://repositorio.cepal.org/handle/11362/6809).
} 
Las políticas públicas de conciliación familiar y laboral no incumben únicamente a mujeres (y hombres) sino a toda la sociedad. Las medidas asistenciales no pueden estar destinadas a madres que trabajan para que concilien. Los planes deben diseñarse para todos: para la madre y su derecho a tener un trabajo digno sin que la situación familiar suponga discriminación alguna; para el padre y su derecho a vivir más intensamente el cuidado de la familia; el derecho de los hijos a ser educados por sus padres; y el de los ancianos y dependientes a estar con sus familiares ${ }^{57}$. Los planes sociales han de diseñarse en términos de corresponsabilidad para forzar el cambio en los roles y estereotipos, y deben ser públicos e independientes de la participación en el mercado.

A renglón seguido, en los años 90, Esping-Andersen estableció tres modelos de gobernanza en función del grado de inclusión del mercado y del estado en las familias $^{58}$. Pese a que en España y en el resto de Europa se tiende a una mayor mercantilización y privatización de los servicios sociales -guarderías, residencias, planes de jubilación, e incluso sanidad y educación-, los estados tienen la obligación de garantizar los mínimos de justicia sociales con independencia del mercado. Más que una obligación es un imperativo moral, porque es una cuestión de justicia. El objetivo debe ser desmercantilizar los servicios asistenciales y de cuidado, y desfamiliariarizar al individuo con políticas sociales para que su integridad no esté sujeta a la solidaridad familiar en caso de estar en situación de dependencia. Lamentablemente, parece que el rumbo es el contrario, y ahora hasta los bancos venden seguros de salud: nos dirigimos hacia el modelo liberal.

\section{Economía feminista para la empresa del siglo XXI}

El patrón de desigualdad persiste en el mercado de trabajo. Según los datos de la OIT (2018), la tasa mundial de desocupación femenina supera a la masculina en 0'8. Desde 1990, la brecha se ha reducido en dos puntos, pero los datos no auguran nada bueno, pues los índices de mejoría se desacelerarán entre 2018 y 2021, y con esto puede que se retroceda o que se invaliden las mejoras logradas en el último

\footnotetext{
${ }^{57}$ E. CAAMAÑO. "Mujer y trabajo: Origen y ocaso del modelo del padre proveedor y la madre cuidadora". En Revista de Derecho de la Pontificia Universidad Católica de Valparaíso. XXXIV (Valparaíso, Chile, 1er Semestre de 2010, pp. 179-209).

${ }^{58}$ Estos son: el régimen liberal (grado mínimo de desmercantilización: prepondera el mercado, y la familia y el estado son marginales). Este sería el caso de EEUU, Canadá, Australia, Nueva Zelanda, Irlanda y Reino Unido; el conservador corporativo, (basado en la solidaridad familiar: da el rol central a la familia, margina al mercado, y al estado le concede una acción subsidiaria de provisión social). Alemania, Francia, Italia y España son un ejemplo; el social-demócrata (grado máximo de desmercantilización: el estado asume el rol central, y la familia y el estado quedan al margen), es propio de los países nórdicos (A. SOJO. "Estado, mercado y familia: el haz del bienestar social como objeto de política”. En CEPAL- SERIE Seminarios y conferencias. 2005, № 46, pp. 149-161. Consultar en https:// repositorio.cepal.org/handle/11362/6809).
} 
decenio en materia de igualdad. Así se muestra especialmente en los países en desarrollo, donde se espera que aumente la brecha de desocupación entre hombres y mujeres ${ }^{59}$, pese a que en los países desarrollados, las tasas de desocupación se acercan a la paridad ${ }^{60}$.

Tal vez derive de aquel inicio de la Odisea, el pensar que las mujeres no son productivas en el trabajo fuera de casa. Este es el mito que hoy en día siguen creyendo los empresarios. Corregimos, los empresarios piensan que las mujeres sí son productivas, incluso más que los hombres, pero en "lo suyo": en trabajos de asistencia y cuidado. Para todo lo demás, las mujeres rinden menos, con independencia de la cualificación que se requiera para el puesto. Y lo son por el mero hecho de ser mujer, ya que, por los deberes familiares, no podrá hacer horas extra, ni trabajar en festivo. Para los empresarios, las demandas de flexibilidad laboral para atender a la familia, embarazos y excedencias suelen ser consideradas anomalías personales para obtener beneficios, dispensas para librarse de las obligaciones. Aunque en realidad, para la persona que los solicita, suponen un prejuicio en su carrera laboral al ser percibida como una persona menos comprometida con la empresa (Abrano y Todaro, 1998).

Podríamos establecer tres tipos de empresas según la relación que mantienen con la perspectiva de género y las necesidades familiares. La primera sería la empresa tradicional-patriarcal: la división sexual establece las funciones de hombres y mujeres. La empresa se considera como una familia, y el patriarca-empresario se siente con derecho de entrometerse en la esfera privada de los empleados, organizándoles la vida y el trabajo según la jerarquía de roles. En segundo lugar, la empresa competitiva y mecanicista, donde prima el resultado. Las relaciones de género son menos familiares que en la cultura tradicional, y las mujeres son aceptadas en puestos importantes solo si son tan duras como los hombres. Sin embargo, las que sobresalen no están vistas como modelos positivos por otras mujeres, y en ocasiones pagan un alto coste en término personales. Es aquí donde se reproduce el modelo de la abeja reina ${ }^{61}$, aquella mujer de perfil conservador que destaca en un mundo de hombres, y que considera que su éxito profesional se debe a méritos propios, olvidando los obstáculos de clase social y género que sufren el resto ${ }^{62}$.

\footnotetext{
${ }^{59}$ En África del Norte y lo Países Árabes, la brecha de multiplica con creces, y más si de población juvenil se trata. El informe de la OIT señala que la limitación de las mujeres al acceso del mercado laboral guardan relación con la carga del trabajo asistencial no remunerado, las responsabilidades familiares, que limitan la formación académica, y el empleo al que se puede acceder.

${ }^{60}$ En regiones de Europa Oriental y América del Norte, la tasa de desocupación masculina es incluso superior. Se achaca a los logros en paridad de género, lo méritos académicos de las mujeres y los efectos negativos de la crisis que afectaron principalmente al sector de la construcción.

${ }^{61}$ O. GARCÍA-VELASCO. Síndrome de la abeja reina. Tesis Doctoral, Facultad de Psicología de la Universidad Complutense de Madrid, 2013. https://eprints.ucm.es/22397/1/T34663.pdf

${ }^{62}$ Simone de Beauvoir ya acuñó el término como mujeres pelota. El entorno en que se desarrollan se ha venido a llamar feminismo corporativo, aquel que reivindica el éxito bajo las reglas libres del mercado.
} 
Por último, la cultura de la transformación requiere la adopción de toda una serie de sistemas flexibles orientados al cliente. No interesa la competitividad a corto plazo, sino que se reconoce el valor de la gente y se busca el empoderamiento personal. La empresa sustenta sus valores en el compromiso recíproco entre la empresa y los trabajadores, y en el cuidado del entorno. Con ello se demuestra que el beneficio no tiene que estar reñido con la ética. En este sentido, se habla además de la necesidad de incorporar estilos de gerencia más femeninos.

Huelga decir que desde una perspectiva de género, es este último modelo el que cumple con los cambios requeridos para el siglo XXI. El imaginario empresarial debe cambiar y permitir otra organización del trabajo que considere la familia y otros aspectos como parte de la vida laboral, de la productividad, que capacite el bienser de las personas y mejore su entorno. Ahora bien, debatir sobre el coste adicional que suponen las mujeres para las empresas no significa negar que no exista, porque las tareas reproductivas y del cuidado sí tienen costes para las empresas. El problema es que la cuestión se ha estereotipado, puesto que la doble jornada es cosa de mujeres y las políticas de conciliación se piensan en femenino. No existe una forma de mediar la productividad de las mujeres, ni de cualquier individuo, porque siempre depende de las condiciones en que se realiza. En el caso de erradicar las desigualdades laborales entre hombres y mujeres, el coste familiar seguiría existiendo, puesto que lo personal es también mercantil, y continuaría afectando a la empresa.

Podemos suponer que las reticencias de la Patronal a abordar el problema se deben al lastre cultural que permite la normalización del control para mantener el orden. Imaginemos que se redefiniesen las relaciones de género en la esfera doméstica: la distribución de las tareas puede tener consecuencias imprevisibles, puesto que los hombres exigirían nuevas demandas laborales. De ser así, se impondría la ortodoxia mitológica de la búsqueda del beneficio y todos sus credos sobre la búsqueda del beneficio en base a la lógica, la eficiencia, el control y el orden, la racionalidad.

La economía es por definición la ciencia que estudia el uso de los recursos, y según el análisis económico clásico, la empresa tiene una meta particular: maximizar en beneficio o la utilidad. Y para lograrlo, reduce la racionalidad operativa al cálculo monetario. Esta racionalidad empresarial incluye conceptos, reglas, criterios con los que trabajan la teoría y la praxis económica. Todos ellos utilizan modelos matemáticos, con lo que la consecuencia es la visión positivista que nos hace separar lo económico de lo social. Es por esto que la mayoría de los análisis desde el campo liberal y marxista entienden la actividad económica con independencia 
de la actividad social ${ }^{63}$. Primero hay que tener las cuentas claras, y después ya nos ocuparemos de todo lo demás. Con todo, los problemas sociales se han sacado fuera de la praxis económica y empresarial porque no les incumbe. Así que la igualdad de oportunidades y la ecología puede que sean una exigencia ética, pero nada tiene que ver con la empresa. $\mathrm{O}$ al menos esto es lo que piensan algunos.

Ahora bien, el comportamiento racional nos lleva a alcanzar metas en función de determinadas condiciones y situaciones dadas. Por esto, la racionalidad está condicionada por las metas y el contexto, y por lo tanto su operatividad se puede cambiar. Además, la praxis se construye y se transforman a través de una compleja marcha de avances en el contexto político, económico, cultural y legal. El conocimiento y percepción del entorno, y los paradigmas intelectuales y culturales sustentan un papel importante en los procesos de cambio de los criterios, e influyen en el desarrollo de las instituciones y sus decisiones. En este sentido, la mente humana es flexible, puede adquirir una diversidad enorme de patrones de comportamiento para resolver problemas, adaptarse y sobrevivir. De igual manera, la ductilidad empresarial debe imponerse para buscar y experimentar nuevas rutinas operativas.

En este sentido, la economía feminista ${ }^{64}$ surgió en los años noventa para cuestionar los modelos de la teoría neoclásica y del marxismo clásico que obviaban las normas patriarcales y relaciones de género causantes de la desigualdad en el trabajo. La economía feminista sugiere que toda la economía puede analizarse desde un punto de vista feminista, y a grandes rasgos, cuatro son sus áreas de acción: visibilizar y denunciar la desigualdad en el campo socio-económico, criticar el capitalismo neoliberal construyendo un modelo alternativo, trabajar en las cuestiones de género relacionadas con temas como la globalización y el desarrollo, y construir alternativas desde ecologismo.

Algo está cambiando sí, pero cambiar los tiempos, la política y los trabajos, no es cambiar no solo la cultura, sino darle la vuelta al sistema económico y social. El activismo feminista reivindica cambios en las calles y las instituciones, y el apoyo del Estado es imprescindible. Urge un pacto político que defienda la conciliación como un mecanismo de inclusión social, equilibre la brecha en términos de igualdad y permita el bienser de las personas. Al igual que lo personal es político, la economía siempre es economía política, así que lo importante es saber quién decide la política, y en esto la sociedad civil tiene la última palabra.

\footnotetext{
${ }^{63}$ D. GARCÍA-MARZÁ. Ética Empresarial del diálogo a la confianza. Trotta: Madrid, 2004.

${ }^{64}$ M. D'ALESSANDRO. Economía feminista: las mujeres, el trabajo y el amor. Ediciones B: Barcelona, 2018.
} 


\section{Algunas conclusiones}

A estas alturas del texto, queda claro que las causas del desequilibro en la toma de decisiones entre mujeres y hombres se encuentran fuera de la empresa. Como institución, la empresa está inmersa en un contexto económico social, y puesto que el género está en todas partes, las prácticas discriminatorias se reproducen también dentro de su organización. Por el mismo motivo, recordemos también que al formar parte de la sociedad, la empresa es una institución social con responsabilidad moral para con la ciudadanía y su entorno, y por tanto, no puede permanecer ajena a los cambios.

$\mathrm{Al}$ inicio recordamos a las primeras feministas francesas. Por aquel entonces, vindicaban su derecho a la ciudadanía: «es tiempo de efectuar una revolución en el comportamiento de las mujeres, tiempo de restaurar su dignidad perdida y de hacerlas trabajar, como parte de la especie, para reformar el mundo con su propio cambio» (Wollstonecraft, 2016: 57). La ciudadanía del siglo XXI exige un nuevo derecho del trabajo forjado en la corresponsabilidad entre la organización y los trabajadores, a fin de desarrollar políticas de igualdad de oportunidades mediante la negociación colectiva. Es preciso avanzar e incorporar nuevos elementos reformadores que contribuyan a potenciar y facilitar la participación de las mujeres en una posición más dinámica y promocional. De la misma manera, es deber de las empresas y derecho de los y las trabajadoras, el tomar conciencia sobre la necesidad de este tipo de políticas, y más si cabe, de un compromiso y voluntad política de todos los actores involucrados.

La economía feminista aboga por un nuevo sistema del bienestar social, más justo y felicitante, cuyas formas de organización social no se pacten dentro del ámbito privado de los hogares y las familias. Rediseñar un nuevo pacto social, político y económico en que la producción y la reproducción supere los clásicos modelos de reparto de responsabilidades en el hogar y el trabajo. La adaptabilidad laboral con horarios flexibles, empleos compartidos semana laboral comprimida, jornada laboral reducida, horas anuales, trabajo a distancia, son algunas de las soluciones que se proponen. Pero, para evitar pensar que todo lo anterior es cosa de mujeres, mejor proponemos remunerar el trabajo doméstico y establecer un ingreso básico de ciudadanía, a partir del cual, establecer los salarios que reflejen los valores de dignidad, autoexpresión, autodesarrollo, y planes de vida. 
La ciudadanía actúa como motor del cambio porque regula la norma política, y ésta, a su vez, incide sobre la realidad social y empresarial. Para muchos, lograr que se equiparen los derechos y deberes entre hombres y mujeres, son tan sólo sueños de utopía. Entonces, seamos realistas y pidamos lo imposible: pidamos la igualdad. 